\title{
Higher Order Continuous SI Engine Observers
}

\author{
Vesterholm, Thomas; Hendricks, Elbert; Houbak, Niels
}

Published in:

American Control Conference

Publication date:

1992

Document Version

Publisher's PDF, also known as Version of record

Link back to DTU Orbit

Citation (APA):

Vesterholm, T., Hendricks, E., \& Houbak, N. (1992). Higher Order Continuous SI Engine Observers. In American Control Conference (pp. 510-515). IEEE.

\section{General rights}

Copyright and moral rights for the publications made accessible in the public portal are retained by the authors and/or other copyright owners and it is a condition of accessing publications that users recognise and abide by the legal requirements associated with these rights.

- Users may download and print one copy of any publication from the public portal for the purpose of private study or research.

- You may not further distribute the material or use it for any profit-making activity or commercial gain

- You may freely distribute the URL identifying the publication in the public portal

If you believe that this document breaches copyright please contact us providing details, and we will remove access to the work immediately and investigate your claim 


\title{
Higher Order Continuous SI Engine Observers
}

\author{
Thomas Vesterholm*, Elbert Hendricks* and Niels Houbak**

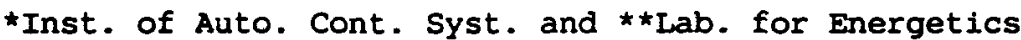 \\ The Technical University of Denmark \\ DK-2800 Lyngby, Denmark
}

\section{Abstract}

A nonlinear compensator for the fuel film dynamics and a second order nonlinear observer for a spark ignition engine are presented in this paper. The compensator and observer are realized as continuous differential equations and an especially designed integration algorithm is used to integrate them in real time. Using these means, accurate steady state and transient air/fuel control can be obtained with excellent robustness properties. Some useful condition monitoring facilities are also available in the observer. The compensator and observer are based on a Mean Value Engine Model (MVM) presented earlier. A MVIM is one which predicts the mean value of the engine states and internal variables over time scales which are large compared to the cyclic engine process.

\section{Introduction}

Two of the main problems involved in obtaining accurate air/fuel ratio control in a spark ignition engine are [1]

1. compensating for the fuel wetting dynamics in the intake manifold (CFI engine) or in the region of the intake valve (EFI engine) and

2. correctly estimating the air mass flow at the fuel injection location.

It has been shown in previous publications that a linear fuel film dynamics compensator and a single state nonlinear observer can be useful for accurate air/fuel ratio control of a Central Fuel Injection (CFI) engine. The fuel film compensator approximately cancels the dynamics of the fuel film and reduces the order of the estimation problem with one state. In order to estimate the air mass flow at the injection location, the observer is necessary. In this way one can avoid the effects of sensor response time, sensor noise and engine modeliling errors $[2,3]$. This paper extends the earlier work in two important ways:

1. a nonlinear compensator for the fuel film dynamics is introduced which improves compensation accuracy and

2. a two state observer is used which has improved robustness properties and greater noise insensitivity.

Both the compensator and the observer are based on earlier work on mean value engine models (MVEM) of SI engines $[4,5]$.

\section{The Mean Value Engine Hodel}

The MVMM for a CFI engine can be written as the following coupled set of nonlinear differential and algebraic equations. For the sake of brevity the equations will only be considered at constant (room) temperature. For the fueling dynamics:

$$
\begin{aligned}
& \ddot{m}_{t 2}=\frac{1}{\tau_{1}}\left(-\dot{m}_{t 2}+x \dot{m}_{t 1}\right)=f_{1}(a, n)(1 a) \\
& \dot{m}_{t v}=(1-x) \dot{m}_{t 1} \\
& \dot{m}_{t}=\dot{m}_{t r}+\dot{m}_{t 2}
\end{aligned}
$$

Here it should be noted that all of the variables in the equations are written in terms of fuel mass flow. This formulation corresponds to keeping track of the fuel mass flow currents in the intake manifold. For the crank shaft dynamics:

$$
\begin{gathered}
\dot{n}=-\frac{P_{f}+P_{p}+P_{b}}{I n}+\frac{H_{u}}{I n} \eta_{1} \dot{m}_{f}\left(t-\Delta \tau_{d}\right) \\
\quad-f_{2}\left(\dot{m}_{E}, n, p_{\text {man }}\right) \\
\Delta \tau_{d}=\frac{60}{n}\left(1+\frac{1}{n_{c y l}}\right)
\end{gathered}
$$

where the variable $\Delta \tau_{d}$ has been introduced. It is the injection/torque build-up time delay. For the manifold pressure:

$$
\dot{p}_{\operatorname{man}}=-\frac{v_{d} n \eta_{\text {vol }}}{120 V} p_{\operatorname{man}}+\frac{R T_{\text {man }}}{V} \dot{m}_{2 f}\left(\alpha, p_{\operatorname{man}}\right)
$$

or

$$
\begin{aligned}
\dot{p}_{\operatorname{man}}--\frac{1}{\tau_{\max }} p_{\operatorname{man}} & +\frac{R T_{\operatorname{man}}}{V} \dot{m}_{a t}\left(\alpha, p_{\operatorname{man}}\right) \\
& =f_{3}\left(\alpha, \Omega, p_{\operatorname{man}}\right)
\end{aligned}
$$

where

$$
\tau_{\operatorname{man}}=\frac{120 \mathrm{~V}}{V_{d} \cap \eta_{\mathrm{vol}}} .
$$

is the large signal manifold pressure time constant.

Equations (1a) - (1c) are very nonlinear for a CFI engine since $X(\alpha)=1-\cos (\alpha)-$ 
$b_{0}$, where $b_{0}$ is a constant. Equations (2a) and (2b) are nonlinear because the dependence of $P_{f}, P_{p}$ and $P_{b}$ on $n$ and $p_{\operatorname{man}}[4,5]$. The last state equation (3) is extremely nonlinear. This is because of the very complicated form of $\eta_{\mathrm{vol}}\left(n, p_{\operatorname{man}}\right)$ and $\dot{m}_{\text {et }}\left(\alpha, p_{\operatorname{man}}\right)[4,5,6]$. In spite of the nonlinearities, the global accuracy of the MVEM is guite good: the relative error in the prediction of the important engine states and internal variables has a standard deviation of less than 28 over the entire operating range of the engine.

\section{Nonlinear Fuel Film Compensator}

In a practical application, a fuel film compensator (or inversion filter) is placed between the fuel flow command and the injector pulse width driver algorithm. Its function is to approximately cancel out the dynamics of the fuel film.

The ideal nonlinear compensator can be derived mathematically by inverting the nonlinear equations of the MVEM fuel film model [6]. Inversion is accomplished using a method similar to that used by Balchen, et. al.. [7] to design a nonlinear series decoupler (or compensator). This gives a inearization by transformation of the fuel film dynamics. In the limit of high closed loop gain, the ideal compensator is obtained.

The nonlinear compensator which corresponds to model in equations (1a) - (1c) above can be written:

$$
\dot{\mathrm{m}}_{t 1}=\frac{\dot{m}_{t u}-r}{1-X}
$$

where the dummy variable $r$ is determined by solving the differential equation

$$
\dot{I}-\frac{1}{T_{t}}\left(-I+X \dot{m}_{t 1}\right) \text {. }
$$

If $1-x$ is not zero then equations (4a) and (4b) are the exact inverse of the model equations. In fact 1 - $x$ does not approach zero for any of the engines which have been identified (including a port injection engine). The compensator is a simple feedback structure and equation (4a) gives the summing point equation times the variable $1 /(1-x)$. Equation (4b) has the same form as a first order low pass filter and is in the feedback loop. Like the fueling dynamics model equations, these equations have a linear form but are nonlinear because of $x$ and $\tau_{f}$. The nonlinear compensator is not dependent on the form or functional dependence of either $X$ or $\tau_{\varepsilon}$. They may be functions of the engine states or inputs and or be otherwise time dependent.
Another very popular simple model for the fueling dynamics is due to Aquino [8]. Using the same notation as above this model can be expressed as

$$
\begin{aligned}
& \frac{d m_{t f}}{d t}=-\frac{1}{T_{t}} m_{t t}+x \dot{m}_{t 1} \\
& \dot{m}_{t v}=(1-x) \dot{m}_{t 1} \\
& \dot{m}_{t}=\dot{m}_{t v}+\frac{1}{T_{t}} m_{t t}
\end{aligned}
$$

In contrast to the pure fuel flow model above, Aquino's model is formulated in such a way that it keeps track of the fuel mass which is stored in the manifold (or in the region of the intake valve). It is based on the assumption that the fuel mass flow from the fuel film due to evaporation is proportional to the mass of the fuel film. The proportionality factor is the reciprocal "time constant". Using the same technique as was applied above, it is possible to derive the exact inverse of the Aquino model. It is

$$
\dot{m}_{f 1}=\frac{1}{1-x}\left(\dot{m}_{f u}-\frac{s}{\tau_{f}}\right)
$$

where the new dummy variable $\mathbf{s}$ is determined by solving the differential equation

$$
\dot{s}=-\frac{1}{T_{t}} s+x \dot{m}_{t 1} \text {. }
$$

This "Aquino" nonlinear compensator has the same structure as does the flow model compensator above, including its linear feedback form.

The two compensators above have a number of common characteristics:

1. they are both mathematically ideal and unique for the given model.

2. because they are based on different physical pictures of the dynamics, they are physically distinct.

3. they have identical responses if $x$ and $\tau_{f}$ are constant.

4. they have identical responses to a linear compensator if $X$ and $\tau_{t}$ are constant. The linear compensator is obtained by using the reciprocal transfer function of equations (4a) - (4c) or (5a) - (5c), assuming that the model parameters are constant $[6]$.

5. they have different responses if $x$ and $\tau$ are not constant.

The "Aquino" nonlinear compensator is the subject of a Hitachi patent [9].

Either of the two nonlinear compensators above or the linear compensator can be used to identify the $x$ and $\tau_{f}$ functions of 
any given engine at any given temperature. This makes it possible to "tune" the filter to the manifold/engine system in question. The method with which this can be accomplished has been reported in several earlier publications $[1,2,3,6]$. Once a compensator has been properly tuned, it should allow the passage of square waves from the injector fuel flow to the engine exhaust. This means that the fuel film dynamics are being canceled over a broad frequency range. Figure 1 shows the response of a small CFI engine with a properIy tuned compensator (equations (4a) (4b)) to a square wave perturbation in the injector fuel mass flow (not shown). The compensated, injected fuel mass flow is shown at the top of the figure (arbitrary units) while the $\lambda$ response is below. The compensator works quite accurately at the given operating point and in fact also works well globally [6].

\section{Continuous Monlinear Observer}

An observer is an obvious solution to the problem of accurate air mass flow estimation in the presence of sensor delays and noise. The reason why observers have not been exploited earlier in engine control applications is the lack of a simple compact dynamic engine model which can be imbedded in a microprocessor. The mean value engine model is an obvious candidate for the basis of a nonlinear engine observer. This is especially true given the system order reduction made possible by the nonlinear compensator.

A nonlinear observer which has good guaranteed robustness properties and is simple enough to realize in a practical system is the constant gain extended Ralman filter (CGERF). An extended Ralman filter for the two state MVBM can be written

$$
\begin{aligned}
& \dot{\mathrm{n}}-\dot{E}_{2}\left(\dot{\mathrm{m}}_{\mathrm{E}}, \hat{A}, \hat{p}_{\operatorname{man}}\right) \\
& +k_{22}\left(n_{m}-\hat{A}\right)+k_{23}\left(p_{\operatorname{man}}-\phi_{m n}\right) \\
& \dot{\phi}_{\operatorname{man}}=\hat{E}_{3}\left(\alpha, \hat{A}, \hat{D}_{\operatorname{man}}\right) \\
& +k_{32}\left(n_{m}-A\right)+k_{33}\left(p_{\operatorname{man}}-b_{\text {man }}\right)
\end{aligned}
$$

where the hats denote state estimates and the " $\mathrm{m}$ " subscripts denote measurements, the $f_{1}^{\prime} s, i=2,3$, are the functions on the right in equations (2a) and (3a) or (3b), and the $k_{i j}^{\prime} s, i, j=2,3$, are elements of the Kalman gain matrix, $R$.

The Ralman gain matrix can be determined from the expression

$$
K=P(t) C(t) R_{2}^{-1}
$$

where $R_{2}$ is the measurement noise covariance matrix, $C$ is the linearized

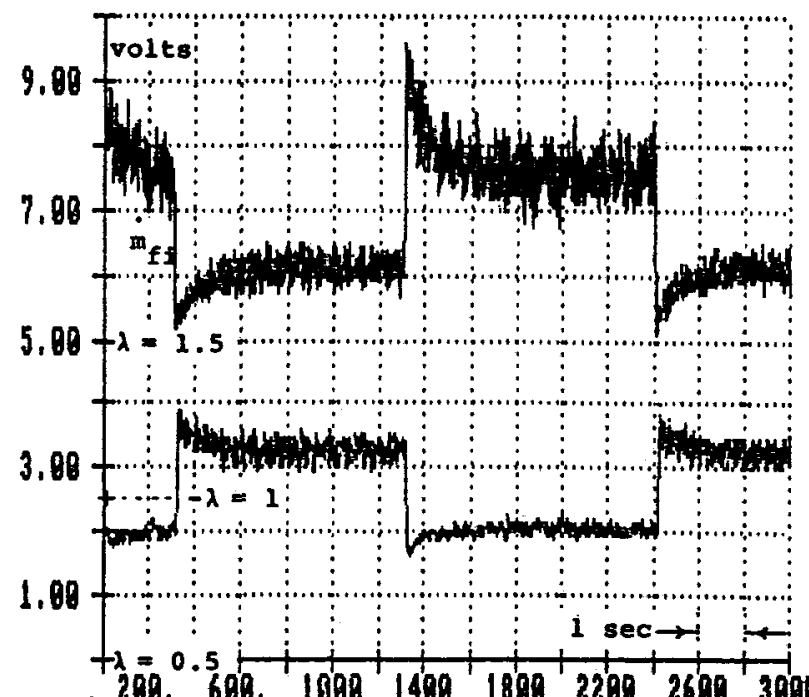

a: $48^{\circ}$

209.600 .108014

$\mathrm{n}$ : $4000 \mathrm{rpm}$

Qb: $53.1 \mathrm{k}$

Figure 1. Results of a validation experiment of the nonlinear fuel film compensator (based on flow model) on a 1.1 I CFI engine. The pre-compensator fuel flow signal was a square wave (not shown). After tuning $X$ and $\tau_{f}$ at five arbitrary power levels, the compensator was tested for proper performance over the engine's entire power range. $X$ was a function of $\alpha$ and $\tau_{f}$ was a constant. The post-compensator fuel mass flow is at the top of the figure in arbitrary units: note the characteristic peaked response. At the engine exhaust a square wave was measured in the lambda signal: it was a square wave as was the input. The results shown were the poorest observed over the entire operating range of the engine.

observation matrix and $P(t)$ is the constant, positive definite solution to the time independent Riccati equation

$$
\begin{aligned}
0-A(t) & P(t)+P(t) A^{T}(t) \\
& -P(t) C^{T}(t) R_{2}^{-1} C(t) P(t)+R_{1}
\end{aligned}
$$

where $A(t)$ and $C(t)$ are the linearized system and output matrices respectively (at a selected operating point) and $R_{\text {, is }}$ the state noise covariance matrix. Note that here $C=I_{2}$. Now if the constant matrices $R$ and $P$ satisfy the ineguality

$$
\begin{aligned}
\left(A-\nabla_{x} f(x, u)\right. & \left.-K\left(C-\nabla_{x} h(x, u)\right]\right) \\
& +\frac{1}{2}\left(R_{1}+P C^{\top} R_{2}^{-1} C P\right)>0
\end{aligned}
$$

then the CGEKF will be nondivergent. Here

$$
x=\left[n, p_{\operatorname{man}}\right]^{T}, u=\left[\dot{m}_{f 1}, \alpha\right]^{T}, \nabla_{x} f \text { and }
$$

$\nabla_{x} h$ are the Jacobians of the system and output functions respectively over the relevant operating range. For a formal 
proof of the statements above see [10].

For a typical SI engine, the state noise sources are basically deterministic, being a close approximations to sine waves. Moreover the measurement noise is relatively small for both the crank shaft speed and the manifold pressure. Thus it is simple to insure that equations (9) and (10) are satisfied over the entire operating range of an engine. This procedure yields an extremely robust observer, especially since the underlying model is so accurate in itself. For practical use, when following fast throttle angle transients, it may be necessary to introduce a switch to reduce the Kalman gain in the observer [11].

\subsection{Observer Realization}

Because of the strong nonlinearities inherent in the MVEM, it is necessary to give careful attention to how it is to be descretized for microprocessor implementation. Because it is desirable to maintain the physical nature and form of the MVEM equations, the most attractive descretization technique is via numerical integration methods (NIMs). A complication which immediately arises in this connection is that an engine has eigenfrequencies which are highly operating point dependent and which are widely separated in frequency. In other words an engine is a stiff system, the eigenfrequency ratio being on the order of 3-1000. The lower ratios occur at the low power operating points.

It can be shown that in order that the descretized observer will have the same properties as the continuous observer, three requirements must be met: 1 . the Lipschitz condition must hold for the observer equations over the entire operating range, 2. the theoretical solution to the observer differential equations must be stable and 3 . the step length, $h$, must be selected is such a way that the solutions to the observer equations remains inside the region of absolute stability of the NIM throughout the integration interval. It can also be shown that the Lipshitz condition does hold for all physically realizable solutions to the observer equations. Further it can be shown that the CGEKF is nondivergent and thus stable over the entire operating range of the engine (see above). As for the last requirement, 3., it can be satisfied simply by choosing an appropriate step length.

In order to determine the absolute stability region of a NIM one usually considers the test problem

$$
\dot{x}=\lambda^{\prime} x
$$

where $\lambda^{\prime}$ is the eigenfrequency. The theoretical solution is stable when Re|$\lambda^{\prime} \mid<$
0. Using for example the explicit Euler NIM one obtains

$$
\begin{gathered}
x(t+h)-x(t)-h \lambda^{\prime} x(t) \\
\frac{x(t+h)}{x(t)}=\left(1+h \lambda^{\prime}\right)
\end{gathered}
$$

where $h$ is the sampling time interval. clearly the numerical solution will be stable when $\left|1+h \lambda^{\prime}\right|<1$. The region for absolute stability of the explicit Euler NIM is shown as the heavily shaded region in figure 2. The intuitively obvious first choice of the Euler method is an unfortunate one because the minimum effective time constant of the manifold pressure is 0.4 msec. From the analysis above, the maximum allowed sampling period is $0.8 \mathrm{msec}$. This will impose a very heavy computational burden on the engine control microprocessor.

To increase the step length, one can resort to a more complex one step method. One can for example consider two or three stage, one step, Runge-Kutta NIM. Such algorithms are attractive because they are relatively simple but can be optimized to increase their absolute stability regions along the negative real $h \lambda^{\prime}$ axis. In previous work a two stage $R-K$ algorithm was used [3]. Better perfomance can be obtained with a three stage, one step, R-K NIM:

$$
\begin{aligned}
& x(t+h)=x(t)+c_{2} h K_{2}+c_{2} h K_{2}+c_{3} h K_{3} \\
& K_{1}=f(x(t), u(t)) \\
& K_{2}=f\left(x(t)+a_{21} h K_{1}, u(t)\right) \\
& K_{3}=f\left(x(t)+a_{31} h K_{1}+a_{32} h K_{2}, u(t)\right)
\end{aligned}
$$

where the subscripted variables are constants and the other variables are given below the difference equation. If one defines

$$
\begin{aligned}
& a=a_{21} c_{2}+a_{31} c_{3}+a_{32} c_{3} \\
& b=a_{21} a_{32} c_{3} \\
& 1=c_{1}+c_{2}+c_{3}
\end{aligned}
$$

and one again considers the test problem in equation (11), one obtains the condition

$$
\left|1+h \lambda^{\prime}+a\left(h \lambda^{\prime}\right)^{2}+b\left(h \lambda^{\prime}\right)^{3}\right|<1
$$

which defines the region of absolute stability for the three stage, one step, R-R NIM. By selecting the correct values of the variables $a$ and $b$ in equation (15), it is possible to obtain a eight-fold increase in the region of absolute stability with respect to the explicit Euler algorithm. This is shown in figure 2 as the lightly shaded region. In this way it was possible to obtain a sampling period 
for stable integration of the two state, CGEKF of $10 \mathrm{msec}$. Such a sampling period is compatible with a PC-AT (286) multitasking system which was evolved at the Danish Technical University as an engine control development system (ECDS) [12].

\section{Experimental Results}

A 1.3 I CFI engine was mounted on a dynamometer. An engine control system containing the nonlinear compensator (equations (4a) - (4b)) and the nonlinear observer of section 4 was realized in the PC ECDS for the engine. The sampling period was 10 msec and the controller software was written in Pascal. Tables in the observer were calculated directly from the MVEM without trimming.

The result of a fast throttle angle transient applied to the controller and engine is shown on figure 3 . The rise time of the throttle angle is about $100 \mathrm{msec}$ and the fall time is about $300 \mathrm{msec}$. Manifold pressure changes are on the same order because of the very fast effective time constant of equation (3a) [6]. This of course results in a very nonlinear response, both in the air mass flow (not shown) and the crank shaft speed. The dynamometer is set here to keep the crank shaft speed approximately constant but it is poorly damped. It is clear that in spite of the size and speed of the transients applied, there are no large lambda spikes apparent at the engine exhaust. There is also no tendency for the lambda signal to over or undershoot the desired steady state lambda value of one. This experiment and a number of others like it (at different operating points) confirm that accurate global air/fuel ratio control is possible using the nonlinear compensator and observer.

In additional real and simulation experiments revealed that the observer was extremely robust with respect to engine parameter variations and initial conditions. The robustness levels found corresponded to those guaranteed in [10]. No experimental evidence of divergence of the CGEKF has ever been observed.

\subsection{Engine Condition Monitoring}

In a block diagram of the CGEKF it can be seen that the large signal time constants $1 / \tau_{\mathrm{m}}$ and $1 / \tau_{\operatorname{man}}$ are in parallel with the crank shaft speed and manifold pressure state integrators. Moreover

$$
\frac{1}{\tau_{a}}-\frac{P_{b}}{I n} \propto Q_{b} \text { and } \frac{1}{\tau_{\operatorname{man}}}-\frac{V_{d} \eta_{v o l} n}{120 V} \propto \eta_{v o l} \text {. }
$$

The observer feedback is effectively in parallel with these large signal time constants. This makes it possible to obtain estimates of the engine load torque (or the engine load power) and the

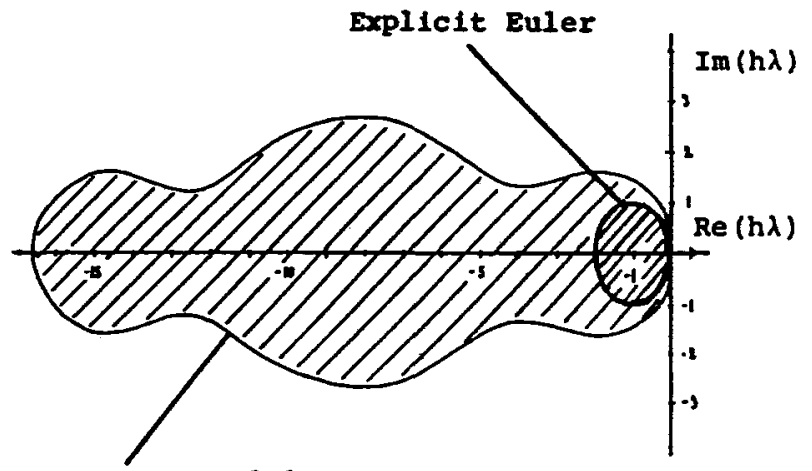

Runge-Kutta 3-1

(optimized)

Figure 2. The region of absolute stability of the explicit Euler and optimized three stage, one step Runge-Rutta integration algorithms.

volumetric efficiency online.

The innovations are introduced into the summing points in front of the state integrators (see equations (2a) and (3a)). If the diagonal Kalman gain matrix elements are relatively large compared to the non-diagonal matrix elements, the diagonal innovation terms of the two state observers contain estimates of the engine load torque and the quantity $\left(\eta_{\text {vol }} n p_{\text {man }}\right)$.

It was found that it was possible to estimate the load torque to an accuracy of \pm 28 over the operating range of the engine. The estimation accuracy of the volumetric efficiency was poorer: on the order of $\pm 5-108$.

\section{Conclusions}

The results which have been presented make it clear that in order to maintain a predetermined air/fuel ratio during fast transients, there must be accurate compensation for the fuel film and manifold filling dynamics. The first problem can be solved using a nonlinear compensator while the second can be solved with a nonlinear observer. These conclusions are fully supported globally on a small CFI SI engine by dynamometer experiments during fast $(100-200 \mathrm{msec})$, large $\left(10-35^{\circ}\right)$ throttle angle transients at many initial and final operating points. Some useful condition monitoring facilities are also available in the observer.

\section{Momenclature}

The following symbols are used in this paper:

$\begin{array}{ll}t & \begin{array}{l}t i m e \text { (sec) } \\ \dot{m}_{\text {eu }}\end{array} \\ & \begin{array}{l}\text { fuel flow command signal } \\ \text { (kg/sec) (fuel film compensator }\end{array}\end{array}$



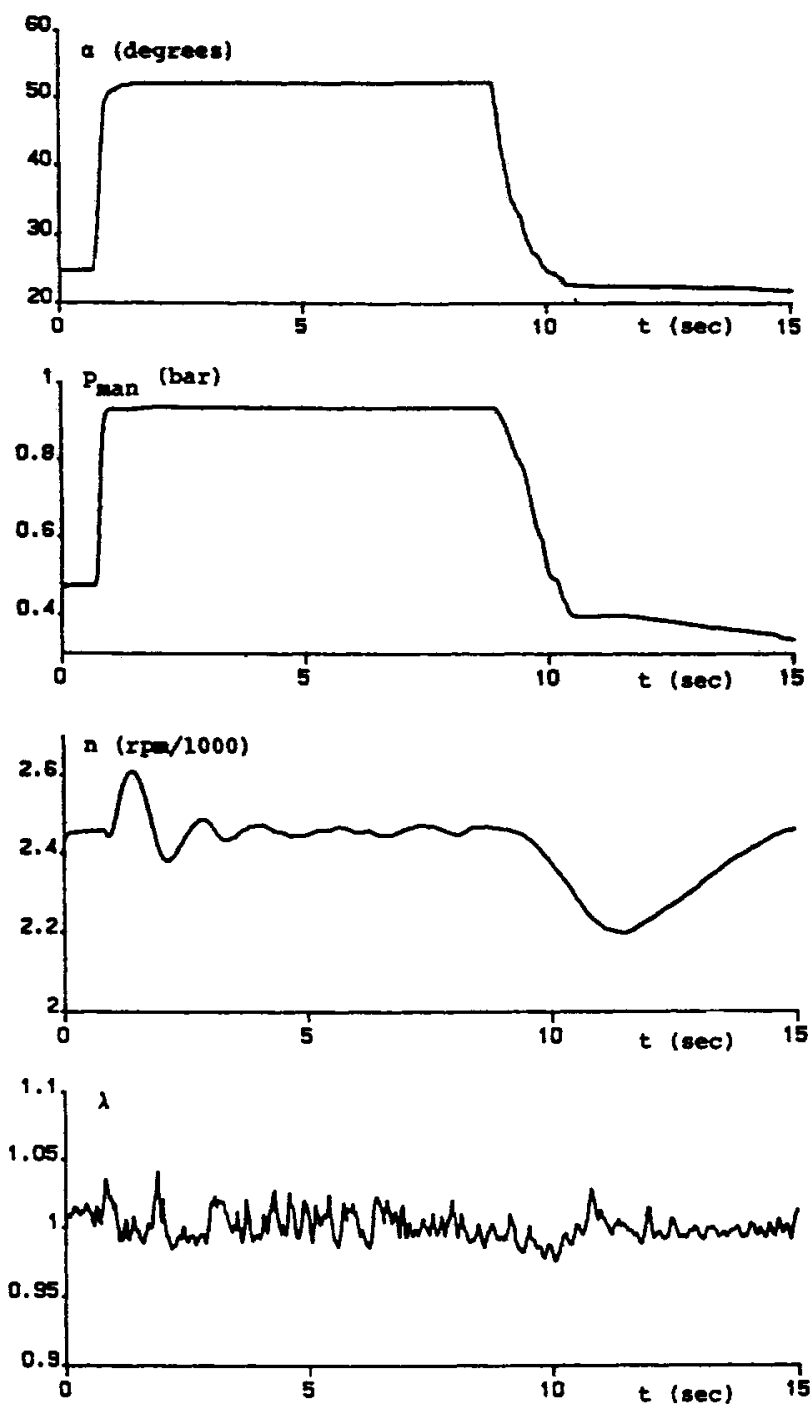

Figure 3. Time responses observed for an engine under control of the nonlinear fuel film compensator and the nonlinear observer (CGERF) described in the text. Note that even with the very fast tip-in/out transients applied, the measured exhaust airlfuel ratio remains close to 1 as desired.

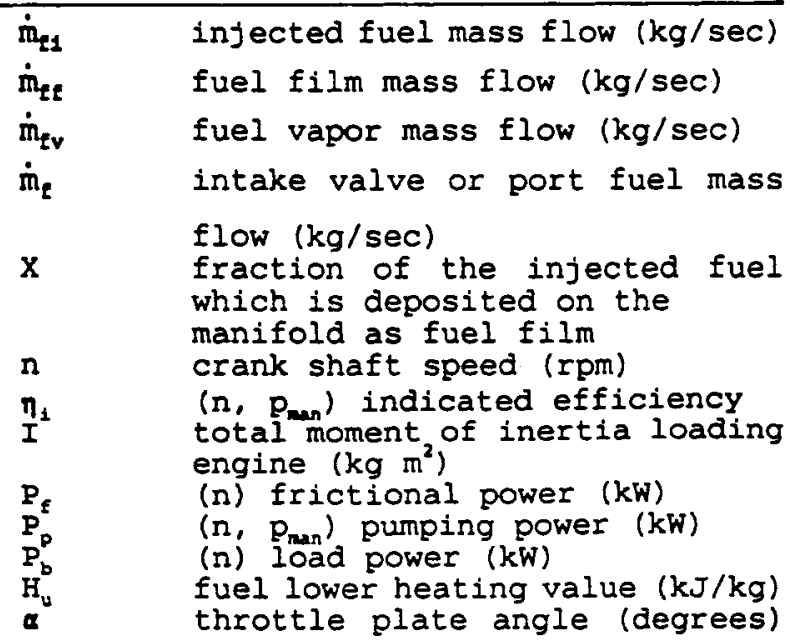

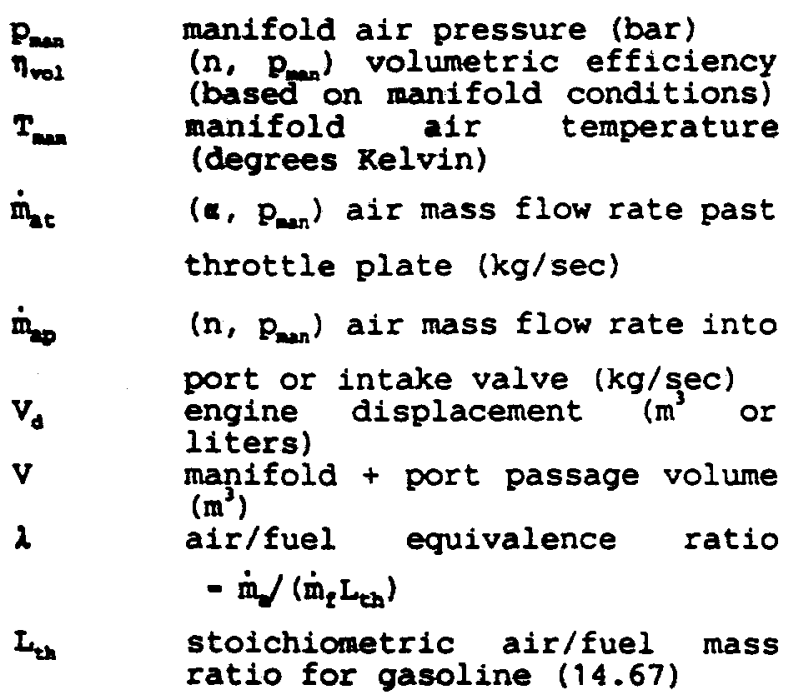

\section{References}

[1] Hendricks, E., and Sorenson, S. C., "SI Engine Controls and Mean Value Engine Modelling", SAE Technical Paper No. $910258,1991$.

[2] Hendricks, E., "Transient Errors in Classical SI Engine Controllers", 1991 ACC, Paper No. TP14, 15:00-15:30, Boston, MA, June, 1991.

[3] Vesterholm, T. and Hendricks, E. "Continuous SI Engine Observers", 1991 ACC, Paper No. TP14, 15:30-16:00, Boston, MA, June, 1991.

[4] Hendricks, E., and Sorenson, S. C., "Mean Value Modelling of Spark Ignition Engines", SAE Technical Paper 900616, 1990.

[5] Hendricks, E., and Sorenson, S. C., "Mean Value SI Engine Model for Control Studies", 1990 ACC, Paper No. TP10, 6:006:30, San Diego CA, May, 1990.

[6] Hendricks, E., and Vesterholm, T., "The Analysis of Mean Value SI Engine Models", SAE Technical Paper No. 920682, 1992.

[7] Balchen, J. G., Lie, B. and Solberg, I., "Internal Decoupling in Nonlinear Process Control", MIC, Vol. 9, No. 3, 1988.

[8] Aquino, C. F., "Transient A/F Control Characteristics of the 5 Liter Central Fuel Injection Engine", SAE Technical Paper No. 810494, 1981 .

[9] United States Patent No. 4,939,658, 3 July 1990. Assignee: Hitachi, Ltd., Tokyo, Japan.

[10] Safonov, M. G., and Athens, M., "Robustness and Computational Aspects of Nonlinear Stochastic Estimators and Regulators, IEEE Trans. on Auto. Cont., Vol. AC-23, No. 4, 1978.

[11] Hendricks, E., Vesterholm, T., and Sorenson, S. C., "Nonlinear, Closed Loop, SI Engine Control Observers", SAE Technical Paper No. 920237, 1992.

[12] Lillelund, J., and Hendricks, E., "A PC Engine Control Development System", SAE Technical Paper No. 910259, 1991. 